\title{
In Vitro Genotoxic Effects of Zerumbone and Cisplatin Combination in CHO Cell Lines
}

\author{
Adel Sharaf Al-Zubairi ${ }^{1,2}$
}

${ }^{1}$ Department of Laboratory Medicine, Faculty of Applied Medical Sciences, Albaha University, Al-Baha, Kingdom of Saudi Arabia. ${ }^{2}$ Department of Biochemistry and Molecular Biology, Faculty of Medicine and Health Sciences, Sana'a University, Sana'a Yemen.

\begin{abstract}
Objective: Several natural products are being increasingly used in the treatment of cancer to minimize the adverse side effects of cancer chemotherapy. Zerumbone (ZER), the sesquiterpene derived from Zingiber zerumbet Smith, has been reported to have an in vitro anticancer effects against various human tumour cells as well as in vivo against a number of induced malignancies in mice. Previously we have reported the genotoxic effects of ZER in vitro against $\mathrm{CHO}$ cell lines. Material and Method: The aim of this study was to investigate the genotoxic effects of the combination of ZER along with cisplatin in $\mathrm{CHO}$ cells. Two cytogenetic endpoints were used, namely Chromosomal Aberrations assay (CA) and Micronucleus test (MN). Both cytogenetic endpoints were performed without any metabolic activation. Result: ZER treated cultures showed the significant increase in the frequency of the chromosome aberrations and $\mathrm{MN}$ induction. In CA assay, marked changes have been observed after co-treatment of $\mathrm{CHO}$ cell lines with different concentration of ZER along with $5 \mu \mathrm{M}$ Cisplatin when compared to ZER treatment alone, suggesting a possible synergistic genetoxic effects. Whereas, treatment of CHO cell lines with different concentrations of ZER along with $2.5 \mu \mathrm{M}$ Cisplatin was found to reduce chromosomal aberrations, suggesting an antagonistic genotoxic effect. On the other hand, in MN induction test, co-treatment of $\mathrm{CHO}$ cell lines with both $2.5 \mu \mathrm{M}$ and $5 \mu \mathrm{M}$ Cisplatin and different concentration of ZER found to reduce the genotoxic effects compared to the $2.5 \mu \mathrm{M}$ and $5 \mu \mathrm{M}$ Cisplatin alone suggesting an antagonistic genotoxic effect. Conclusion: The genotoxic effects of combined low concentrations of Cisplatin with different concentrations of ZER could have an antagonist genotoxic potential in vitro in $\mathrm{CHO}$ cell lines.
\end{abstract}

Keywords: Zerumbone- Cisplatin- CAs- MNi- CHO cell lines- genotoxicity

Asian Pac J Cancer Biol, 2 (4), 101-107

\section{Introduction}

Among the most serious possible side effects of the anticancer chemotherapeutic drugs is their genotoxicity effect which may consequently lead to the development of secondary malignancies. Despite the curative activity in patients with testicular, head and neck or ovarian cancers, cisplatin was shown to have nephrotoxic and neurotoxic side effects [1]. Cancer chemotherapy directly or indirectly affects not only the target tumour cells, but non-tumoural cells DNA structure and function also affected. These effects on the DNA appear primarily in the form of alterations of the DNA structure as a result of alkylations, cross-links, or formation of DNA adducts, which subsequently leads to DNA repair mechanisms.
Submission Date: 09/10/2017Ａcceptance Date: 11/25/2017

\footnotetext{
Corresponding Author:

Dr. Adel Sharaf Al-Zubairi

Laboratory Medicine, Faculty of Applied Medical Sciences, Albaha University, Al-Baha, Kingdom of Saudi Arabia.

Biochemistry and Molecular Biology, Faculty of Medicine and Health Sciences, Sana'a University, Sana'a Yemen.

Email: adelalzubairi@hotmail.com
}

These DNA breaks results as a consequence of DNA repair mechanisms that could be considered as important markers of genotoxicity [2]. Cisplatin or cis-diamminedichloroplatinum II considered one of the most promising and widely used platinum-based therapeutic anti-cancer drugs in clinical practice [3-4]. Its therapeutic effect is attributed to the formation of adducts with DNA [5], that are not removed and may block DNA replication and transcription. It has also been reported that cisplatin may inhibit the activity of telomerase [6].

Herbal medicine has been practiced since ancient times in traditional medicine, in the form of raw plant material or plant extracts [7]. The considerable attention gained by the herbal medicine is due to the premise that these herbal plants contain natural substances that can promote health 
and eliminate the disease. Previous studies have reported that about half the population of many industrialized countries use complementary and alternative medicine, and the proportion is as high as $80 \%$ in many developing countries [8]. According to the World Health Organization, $80 \%$ of the earth population use herbal formulations in traditional medicine [9]. Plant-derived therapies represent $25 \%$ of the drugs prescribed worldwide, and 121 of these compounds still used in the treatment of diseases [10].

Zingiber zerumbet Smith, the wild ginger, belongs to Zingiberaceae family and is native to South East Asia, and is locally known in Malaysia as 'lempoyang'. It's widely cultivated in village gardens throughout the tropical and subtropical area and its rhizomes with the active ingredient, zerumbone (ZER), is used in some South East Asian countries as anti-inflammation while the shoots are used as condiments. The activity of ZER has recently drawn the attention of many researchers due to its activity towards many diseases in vitro and in vivo. Many published researches have reported the antitumour effects of zerumbone in different cancer cell lines, including ovarian, colon, breast, myeloid, pancreatic, lung and gastric cancers [11-19]. Our previous work in vivo, we have reported the activity of ZER against DES-induced mice Cervical Intraepithelial Neoplasia (CIN) [20]. In addition, It has been reported to inhibit both azoxymethane-induced rat aberrant crypt foci and phorbol ester-induced papilloma formation in the mouse skin cancer [21].

In chemotherapy, the use of the combination of two anticancer agents often has the advantage of minimizing the toxicity due to lowering the drug dosage as well as reducing the development of drug resistance by the cancer cells, providing the ability of synergism between drugs with different mechanism of action. In combination chemotherapy, non-toxic or less toxic phytochemicals are combined with chemotherapy agents to enhance the efficacy and reduce the toxicity to normal tissues [22], therefore anticancer phytochemicals are being studied as possible candidates for their synergistic efficacy in combination with the anticancer chemotherapy [22-24].

In this study, we attempted to report the results obtained, for the first time, on the genotoxic effects of the combination of both ZER and Cisplatin in Chinese hamster ovary $(\mathrm{CHO})$ cell lines, by using chromosomal aberrations assay (CAs) and micronucleus (MN) formation as cytogenetic endpoints. This paper describes the results of those investigations and comments on the in vitro genotoxic effects of the combination of both $\mathrm{ZER}$ and Cisplatin in $\mathrm{CHO}$ cell line.

\section{Materials and Methods}

\section{Zerumbone extraction}

ZER was extracted in the laboratory of cancer research MAKNA-UPM, University Putra Malaysia, from the rhizomes of Zingiber zerumbet plant. The fresh rhizomes obtained from the wet market in Kuala Lumpur, Malaysia. Methanol extraction and column chromatography (CC) method were used to extract, isolate and purify the compound. The isolated and purified ZER crystals were subjected to High-Performance Liquid Chromatography (HPLC) and Liquid Chromatography-Mass Spectrometry (LCMS) to confirm its purity and molecular weight. A stock solution of ZER is prepared immediately before use in absolute ethanol (HmbG Chemicals).

\section{Chemicals}

Mitomycin C (MMC), Cytochalasin B (CB [CAS 4930-96-2] and Cisplatin [CAS 15663-27-1] were obtained from Sigma, Giemsa stain [CAS 67-56-1] and Colcemid from (PAA Laboratories).

\section{Chromosomal aberration assay}

In genotoxicity testing, the ability of the chemical to induce the formation of chromosomal aberrations and damage as well as gene mutations is investigated. Therefore ZER was evaluated for its potential to produce chromosome aberrations in $\mathrm{CHO}$.

\section{CHO cell lines}

Chinese hamster ovary $(\mathrm{CHO})$ cells were purchased from ECACC (UK). The atypical cell contains 21 chromosomes. The cells grow as an adherent monolayer in appropriate tissue culture vessels, doubling approximately every 12 hours. Health status of the cultures was monitored throughout each experiment by cell counting and microscopic observation. Cells were maintained in RPMI 1640 medium (PAA Laboratories $\mathrm{GmbH}$, Germany) supplemented with $10 \%$ foetal bovine serum (PAA Laboratories GmbH, Germany). Sterile Nunc tissue culture flasks (Nunc, Denmark) were used. The cells were incubated in a humidified tissue culture incubator at $37^{\circ}$ $\mathrm{C}$ and $5 \% \mathrm{CO}_{2}$. When the cells reached approximately $60-80 \%$ confluence, they were dislodged with $0.05 \%$ trypsin (PAA Laboratories GmbH, Germany), collected by centrifugation and seeded in fresh medium. Each trypsinization was recorded as one passage. A continued culture of $\mathrm{CHO}$ cell line (passage15) was used. On the day before the experiment, approximately $5 \times 10^{5}$ cells from a culture with approximately $60-80 \%$ confluence were seeded into each T- $25 \mathrm{~cm}^{2}$ (Nunc, Denmark) flasks. The cells were incubated overnight in a humidified incubator at $37^{\circ} \mathrm{C}$ and $5 \% \mathrm{CO}_{2}$.

\section{Treatment with the test substance}

Tested compound was prepared as a $1 \mathrm{mg} / \mathrm{ml}$ stock solution in absolute ethanol just prior to use and a dosing volume of stock concentration diluted with medium ensured a final ethanol concentration of $<1 \%$. The overnight cell cultures were examined under an inverted microscope. They appeared healthy, well adherent, evenly distributed and 60-80\% confluent. Duplicate cultures were prepared for each test substance concentration and controls. Control cultures were handled in a manner identical to the treated ones. Mitomycin-C (Sigma, Germany) was used as a positive control. The treatment medium was $5 \mathrm{ml}$ of the cell culture medium with $10 \%$ foetal bovine serum, with the treatment concentration or a control solute. The final concentrations were 5, 10, 
20, 40.0 and $80 \mu \mathrm{M}$ and the cells were incubated in the treatment medium for 24 hours.

\section{Cells Harvest and Preparation of chromosome slides}

The cells were harvested at the end of treatment and two hours prior to harvesting, colcemid (PAA Laboratories $\mathrm{GmbH}$, Germany) was added at $0.2 \mathrm{ml}$ to arrest cells in metaphase. After this, the medium with suspended cells was transferred into centrifuge tubes. The remaining cell monolayer was dissociated with $0.05 \%$ trypsin and pooled with the collected cell suspension. The cells were centrifuged at $800 \mathrm{rpm}$ and were resuspended with phosphate buffered saline (Sigma) and then collected by centrifugation, swelled in $0.075 \mathrm{M} \mathrm{KCl}$ (Sigma) and fixed in a 3:1 mixture of methanol and glacial acetic acid for three times. Next, the tubes were centrifuged for 5 min, the supernatant discarded and the cell suspension dropped onto pre-chilled slides previously cleaned with non-toxic detergent and soaked in distilled water at $5^{\circ} \mathrm{C}$. Chromosome slides were prepared, air-dried and stained in 6\% Giemsa stain ([CAS 67-56-1] Gibco, Invitrogen, Germany). For each duplicate culture, at least 1000 cells were examined to score mitotic index. The mitotic index (MI) was calculated as the percentage of cells at the mitotic stage. Relative mitotic index (RMI) was calculated as:

$\mathrm{RMI}(\%)=$ test concentration $\mathrm{MI} /$ solvent control $\mathrm{MI} \times 100$

\section{Analysis of chromosome aberrations}

All slides were randomly coded. Well-spread metaphase cells with 19-23 chromosomes were analysed for chromosome aberrations as defined. At least 200 metaphase cells from each negative control and ZER-treated culture (100-400 cells per concentration were scored). The number of each type of aberration and the percentage of cells with aberrations was recorded and summarized. The number of chromatid gaps and chromosome gaps was recorded when encountered, but not included in the calculations. This practice concerning gaps has been used [25], as discussed in literary sources. The percentages of cells with aberrations from each concentration were compared to the solvent control values using $\chi 2$ analyses.

\section{Micronucleus test (MN) in CHO}

Chinese hamster ovary $(\mathrm{CHO})$ cells grow as an adherent monolayer in appropriate tissue culture vessels and were maintained in RPMI 1640 medium (PAA Laboratories, Germany) supplemented with 10\% foetal bovine serum (PAA Laboratories, Germany). The cells were incubated in a humidified tissue culture incubator at $37^{\circ} \mathrm{C}$ and $5 \% \mathrm{CO}_{2}$. The overnight cell cultures were examined under an inverted microscope. Duplicate cultures were prepared for each test substance concentration and controls. Control cultures were handled in a manner identical to the treated ones. Mitomycin-C (Sigma) was used as a positive control. The treatment medium was $5 \mathrm{ml}$ of the cell culture medium with $10 \%$ foetal bovine serum, with the treatment concentration or a control solution and the final concentrations were 5, 10, 20, 40 and $80 \mu \mathrm{M}$ ZER. Cells were cultured in the treatment medium for 24 hours. After treatment, cells were washed twice with $10 \mathrm{~mL}$ PBS, trypsinized with $0.05 \%$ trypsin and centrifuged for $5 \mathrm{~min}$ at $800 \mathrm{rpm}$. CHO cells were then harvested and scored using the same method of human lymphocytes micronucleus mentioned above.

\section{Statistical analysis}

Statistical analysis was performed using SPSS 23. Results were analyzed using Chi-square analysis. All statistical tests were performed at the $\mathrm{p}<0.05$ level of significance.

\section{Results}

\section{Mitotic index analysis}

A twofold series of six concentrations of ZER was determined based on the $\mathrm{IC}_{50}$ obtained from the MTT cytotoxicity assay [13]. The relative mitotic index (RMI) values (Table 1) revealed the inhibitory effect with all concentrations of ZER. Meanwhile, the mitotic index for all test concentrations was found to be reduced compared to that seen in the untreated control $(\mathrm{P}>0.05)$. On the other hand treatment of $\mathrm{CHO}$ cell lines with both compounds in combination, revealed a marked reduction in $\mathrm{MI}$ and RMI as compared to the control or cultures treated with ZER alone, particularly co-treatment of cell lines with $5 \mu \mathrm{M}$ Cisplatin and different concentrations of ZER as observed in (Tables 2,3).

\section{Chromosome aberrations (CA) assay}

The CA assay, clastogenicity determined was not significantly observed in the untreated control or the solvent-treated control. Positive control (MMC) was

Table 1. CAs Assay of CHO Cell Lines after Treatment with ZER for 24 hrs

\begin{tabular}{|c|c|c|c|c|c|c|c|c|c|c|}
\hline ZER $(\mu \mathrm{M})$ & $\% \mathrm{MI}$ & RMI & $\%$ Ab cells & Gaps & Breaks & Acentric & Translocat & Ring & Di-centric & Endor \\
\hline Ethanol & 6.25 & 100 & 2.16 & 2 & 2 & 0 & 0 & 6 & 3 & 0 \\
\hline 5 & 5.55 & 88 & $35.43 *$ & 0 & 31 & 1 & 17 & 6 & 7 & 0 \\
\hline 10 & $5 *$ & 80 & $28.89 *$ & 2 & 22 & 0 & 7 & 2 & 6 & 0 \\
\hline 20 & $4.7^{*}$ & 75 & $7 *$ & 0 & 1 & 0 & 0 & 2 & 4 & 0 \\
\hline 40 & $5^{*}$ & 80 & $27.07 *$ & 2 & 13 & 0 & 2 & 7 & 10 & 3 \\
\hline 80 & 5.1 & 81 & $25.47 *$ & 1 & 16 & 1 & 2 & 3 & 2 & 2 \\
\hline MMC & $3 *$ & 48 & $47.33^{*}$ & 2 & 49 & 0 & 12 & 5 & 3 & 0 \\
\hline
\end{tabular}

\footnotetext{
* P-value $<0.05$ (compared to vehicle control).
} 
Table 2. CAs Assay of CHO Cell Lines after Treatment with Different Concentrations of ZER in Combination with $2.5 \mu \mathrm{M}$ Cisplatin for $24 \mathrm{hrs}$

\begin{tabular}{|c|c|c|c|c|c|c|c|c|c|c|}
\hline ZER $(\mu \mathrm{M})$ & $\% \mathrm{MI}$ & RMI & $\%$ Ab cells & Gaps & Breaks & Acentrics & Transl & Ring & Dicentrics & Endor \\
\hline 5 & 6 & 96 & 9 & & 2 & & 1 & 2 & 4 & \\
\hline 10 & 5 & 80 & 5 & & & & & 2 & 2 & 1 \\
\hline 20 & 5.5 & 88 & 7 & 1 & 1 & & 1 & 1 & 2 & 1 \\
\hline 40 & 5.4 & 86 & 39 & 5 & 16 & 1 & & & 8 & \\
\hline 80 & $4 *$ & 64 & 6.8 & & 2 & & & & 1 & \\
\hline
\end{tabular}

${ }^{*}$ P-value $<0.05$ (compared to corresponding ZER concentration).

Table 3. CAs Assay of CHO Cell Lines after Treatment with Different Concentrations of ZER in Combination with $5 \mu \mathrm{M}$ Cisplatin for $24 \mathrm{hrs}$.

\begin{tabular}{|c|c|c|c|c|c|c|c|c|c|c|}
\hline ZER $(\mu \mathrm{M})$ & $\% \mathrm{MI}$ & RMI & $\% \mathrm{Ab}$ cells & Gaps & Breaks & Acentric & Translocat & Ring & Di-centric & Endor \\
\hline 5 & $2.3^{*}$ & 37 & 81 & & 33 & 1 & 38 & 5 & 5 & \\
\hline 10 & $1.8^{*}$ & 29 & 93 & & 49 & 2 & 35 & 3 & 4 & \\
\hline 20 & $2 *$ & 32 & 82 & & 46 & & 34 & 2 & 8 & 2 \\
\hline 40 & $2 *$ & 32 & 81.8 & & 5 & & 3 & & 1 & \\
\hline
\end{tabular}

* P-value $<0.05$ (compared to corresponding ZER concentration).

Table 4. MN test, treatment of $\mathrm{CHO}$ cell lines with ZER for 24 hours for Micronucleus test $(\mathrm{MN}) * \mathrm{P}$-value $<0.05$ (compared to vehicle control).

\begin{tabular}{lccc}
\hline Treatment & Binucleated cells (BN) & MNi & $\% \mathrm{MN}$ \\
\hline Ethanol & 1,000 & 12 & 1.2 \\
ZII $0 \mu \mathrm{M}$ & 2,000 & 30 & 1.5 \\
ZII $5.0 \mu \mathrm{M}$ & 3,000 & 55 & 1.8 \\
ZII $10.0 \mu \mathrm{M}$ & 3,000 & $70^{*}$ & 2.3 \\
ZII $20.0 \mu \mathrm{M}$ & 2,200 & $100^{*}$ & 4.55 \\
ZII $40.0 \mu \mathrm{M}$ & 2,000 & $126^{*}$ & 6.3 \\
ZII $80.0 \mu \mathrm{M}$ & High toxicity & & \\
MMC & 1,000 & $55^{*}$ & 5.5 \\
\hline
\end{tabular}

* P-value $<0.05$ (compared to vehicle control).

significantly shown to induce chromosome aberrations. On the other hand, all the clastogenic indices of ZER were found to induce chromosome aberrations in an increasing dose-response pattern (Table 1). Gaps, breaks as well as endoreduplication, ring chromosomes and dicentrics were the main types of aberration induced by ZER. In treated cultures of $\mathrm{CHO}$ cell line, chromosome breaks were found to be the most prominent aberrations observed whether in the ZER treated or in the combinations of ZER and Cisplatin treated cultures (Tables 1, 2, 3). However, ring chromosomes and dicentrics were also observed to be increased in all treated. The number of aberrant cells with structural aberrations in cultures treated with both compounds were observed to be increased significantly $\mathrm{p}<0.05$ (Table 1 ). Treatment of the cell lines with the lower dose of Cisplatin $(2.5 \mu \mathrm{M})$ together with different concentrations of ZER seems to reduce the percentage of chromosomal aberrations markedly. In contrast treatment of the cell lines with $5 \mu \mathrm{M}$ Cisplatin and different concentrations of ZER enhanced the genotoxic effects as shown in (Tables 2, 3).

\section{MN induction}

Treatment concentrations used in the MN test were $5.0-80.0 \mu \mathrm{M}$ ZER. The potential of ZER and Cisplatin to induce micronuclei is shown in (Tables 4, 5). Treatment of CHO cells with ZER caused dose-dependent $\mathrm{MN}$ induction. An increased number of binucleated cells with micronuclei was found at the higher concentrations ( $>$ $5.0 \mu \mathrm{M}$ ) of ZER and was statistically significantly different from the control (Table 4). In the same time treatment of $\mathrm{CHO}$ cell lines with different concentrations of Cisplatininduced the formation of Micronuclei significantly in all the used concentrations (Table 5). Treatment of $\mathrm{CHO}$

Table 5. Micronucleus test $(\mathrm{MN})$ for $\mathrm{CHO}$ cell lines after treatment with different concentration of Cisplatin for 24 Hours

\begin{tabular}{lccc}
\hline Cisplatin & Binucleated cells $(\mathrm{BN})$ & Micronucleated binucleate $(\mathrm{MNi})$ & $\% \mathrm{MN}$ \\
\hline DMSO & 2000 & 30 & 1.5 \\
$1.25 \mu \mathrm{M}$ & 3000 & 193 & $6.43^{*}$ \\
$2.5 \mu \mathrm{M}$ & 2800 & 145 & $5.2^{*}$ \\
$5.0 \mu \mathrm{M}$ & 3000 & 393 & $13.1^{*}$ \\
$10.0 \mu \mathrm{M}$ & 750 & 147 & $19.6^{*}$ \\
\hline
\end{tabular}

* P-value $<0.05$ (compared to vehicle control). 
Table 6. Micronucleus Test (MN) for CHO Cell Lines after Treatment with Different Concentrations of ZER in Combination with $2.5 \mu \mathrm{M}$ Cisplatin for 24 Hours.

\begin{tabular}{lccc}
\hline Treatment with Cisplatin $2.5 \mu \mathrm{M}$ and ZII & Binucleated cells (BN) & Micronucleated binucleate (MNi) & $\% \mathrm{MN}$ \\
\hline ZII $5 \mu \mathrm{M}$ & 1,000 & 41 & 4.1 \\
ZII $10 \mu \mathrm{M}$ & 1,000 & 38 & 3.8 \\
ZII $20 \mu \mathrm{M}$ & 1,000 & 42 & 4.2 \\
ZII $40 \mu \mathrm{M}$ & 310 & 16 & 5.2 \\
\hline
\end{tabular}

* P-value $<0.05$ (compared to Cisplatin $2.5 \mu \mathrm{M}$ ).

Table 7. Micronucleus test (MN) for $\mathrm{CHO}$ cell lines after treatment with different concentrations of Zerumbone in combination with $5 \mu \mathrm{M}$ Cisplatin for 24 hours

\begin{tabular}{lccc}
\hline Treatment with Cisplatin $5 \mu \mathrm{M}$ and ZII & Binucleated cells (BN) & Micronucleated binucleate (MNi) & $\% \mathrm{MN}$ \\
\hline ZII $5 \mu \mathrm{M}$ & 1,000 & $85^{*}$ & 8.5 \\
ZII $10 \mu \mathrm{M}$ & 1,000 & $98^{*}$ & 9.8 \\
ZII $20 \mu \mathrm{M}$ & 1,000 & $62^{*}$ & 6.2 \\
ZII $40 \mu \mathrm{M}$ & High toxicity & & \\
\hline
\end{tabular}

* P-value $<0.05$ (compared to Cisplatin $5 \mu \mathrm{M}$ ).

cell lines with combination of both compounds, ZER and Cisplatin-induced increase in micronuclei formation but only in the $5 \mu \mathrm{M}$ Cisplatin with different ZER concentrations, while co-treatment of the cell lines with $2.5 \mu \mathrm{M}$ Cisplatin and different concentrations of ZER produced even lower $\mathrm{MNi}$ formation than the $2.5 \mu \mathrm{M}$ Cisplatin alone (Tables 6, 7).

\section{Discussion}

The purpose of this study was to evaluate for the first time, the genotoxic effects of the combination of ZER and the classic chemotherapeutic agent, Cisplatin in $\mathrm{CHO}$ cell lines in vitro. The investigation was conducted using the chromosome aberration assay and micronucleus test as cytogenetic endpoints. ZER alone induced higher CAs frequencies as compared to control values as well as micronucleus formation as revealed by the CA assay and $\mathrm{MN}$ test as reported recently [26]. Thus results found, at least under the experimental conditions used, showed the ability of this compound to induce genotoxicity in vitro in rodent cells. Genotoxic agents can interact with DNA causing damage that result in chromosomal morphological changes called chromosomal aberrations (CA). CAs occurs in proliferating cells and is regarded as a manifestation of damage to the genome. CAs assay is commonly used as a test of mutagenicity in order to evaluate cytogenetic responses to chemical exposure. The present study confirms our previous report [26-27] that ZER significantly decreased the mitotic index in cultures of human peripheral lymphocytes and Chinese hamster ovary cell lines. The concentration range of 5.0-20.0 $\mu \mathrm{M}$ was observed to decrease the mitotic index at the significant level of $\mathrm{P}<0.05$ in contrast to the lower and higher concentration levels which found not to significantly reduce the mitotic index.

The genotoxic effects of the combination of test compounds, ZER and $2.5 \mu \mathrm{M}$ and $5 \mu \mathrm{M}$ Cisplatin were tested. The tested concentrations were chosen according to the cytotoxicity tests [13-28]. The results of the present study demonstrated that the frequency of breaks, gaps, fragments, dicentrics, and endoreduplication was increased significantly in cultures of $\mathrm{CHO}$ cell lines treated with ZER alone and in combination with Cisplatin when compared with the control. The percentage of total aberrant cells recorded were significantly increased at $\mathrm{P}<0.05$ when compared with untreated control. The percentage of structurally damaged cells in the MMC (positive control) treatment group was statistically increased compared to the solvent control indicating the responsiveness of the cells in this test system.

The genotoxic effects of the combination of both compounds on $\mathrm{CHO}$ cell lines were studied in the present work. Two concentrations of the chemotherapeutic anticancer agent, Cisplatin has been used in this study, $2.5 \mu \mathrm{M}$ and $5 \mu \mathrm{M}$, representing concentrations around the median inhibitory concentration of the drug as we reported previously [13-28]. In CAs assay co-treatment of CHO cell lines with $2.5 \mu \mathrm{M}$ Cisplatin and different concentrations of ZER was found to reduce the incidence of chromosomal aberrations as compared to cultures treated with ZER alone, suggesting an antagonistic potential of ZER against the genotoxic effects of Cisplain. In contrast, co-treatment of $5 \mu \mathrm{M}$ Cisplatin with different concentrations of ZER was shown to increase the percentage of the aberrant cells markedly and hence the genotoxicity of the Cisplatin, suggesting an additive synergistic genotoxic effect of ZER.

$\mathrm{MN}$ assay is another widely used cytogenetic endpoint to investigate in vitro chromosomal damage. The occurrence of micronuclei in treated cells provides a comparatively rapid and sensitive indication of both chromosomal damage and chromosome loss that lead to numerical chromosomal anomalies [29-30]. Micronuclei are chromatin masses in the cytoplasm left behind during the cell division; arise from chromosome fragments at anaphase or from acentric chromosomal fragments. An increase in the percentage of $\mathrm{MN}$ in a population of cells 
indicates chromosomal damage occurred as a result of an exposure to either clastogenic or an aneuploidogenic effects [31]. The results of the present study showed that exposure of CHO cells to ZER or Cisplatin significantly increased the frequency of MN. These results support our previous observations that ZER causes chromosomal damage in Chinese hamster cell lines, indicating its potential to cause genotoxic effects [26-27].

Treatment of CHO cell lines with the combination of $2.5 \mu \mathrm{M}$ Cisplatin and different concentrations of ZER was found to reduce the percentage of $\mathrm{MNi}$ formation when compared to the treatment of the cell lines with Cisplatin alone suggesting an antagonistic gesnotoxic potential of ZER. In contrast, treatment of cultures with $5 \mu \mathrm{M}$ Cisplatin and different concentrations of ZER, result in significantly increased percentage of $\mathrm{MNi}$, however, this increase in the MNi formation is not as much as the effect of the $5 \mu \mathrm{M}$ Cisplatin alone. The effect of ZER to reduce the genotoxicity of Cisplatin at its $\mathrm{IC}_{50}$ concentration could have a beneficial application in co-treatment of cancer with both compounds.

In conclusion, the present results provide evidence that ZER compound in concentrations around the $\mathrm{IC}_{50}$ could have a potential effect in antagonizing the harmful genotoxic effects of the chemotherapeutic anticancer agent, Cisplatin. This genotoxicity effects on cultured Chinese hamster cell line, bringing into highlight the need for further studies to better understand the molecular mechanisms of action of ZER compound for a better comprehension to be used in combination with other anticancer drugs and in particular Cisplatin. Thus results found, at least under the experimental conditions used in the present work, showed the ability of this compound to reduce the genotoxicity of Cisplatin in vitro in $\mathrm{CHO}$ cells.

\section{Acknowledgments}

The author would like to extend his utmost gratitude and appreciation to MOSTI (Ministry of Science, Technology, and Innovation) and The National Cancer Council Malaysia (MAKNA) for providing the research grants IRPA No: 06-02-04-0720-EA001. The author also would like to convey his thanks to Dr. Ahmad Bustamam, for his supervision of this work.

\section{References}

1. Ferguson LR, Pearson AE. The clinical use of mutagenic anticancer drugs. Mutat Res. 1996; 355: 1-12.

2. Eastman A, Barry MA. The origins of DNA breaks A consequence of DNA damage, DNA repair or apoptosis. Cancer Invest 1992; 10: 229-240.

3. Arnesano F, Natile G. Mechanistic insight into the cellular uptake and processing of CisPt 30 years after its approval by FDA Coord. Chem Rev. 2009; 253: 2070-2081.

4. Gomez-Ruiz S, Maksimovic-Ivanic D, Mijatovic S, Kaluderovic GN. On the discovery, biological effects, and use of cisplatin and metallocenes in anticancer chemotherapy. Bioinorg Chem Appl, http://dx.doi. org/10.1155/2012/140284 (14 pp.).

5. Fichtinger-Schepman AMJ, van Oosterom AT, Lohman
PHM, Berends F. Cis-diamminedichloroplatinum(II)induced DNA adducts in peripheral leukocytes from seven cancer patients: Quantitative immunochemical detection of the adduct induction and removal after a single dose of cis-diamminedichloroplatinum(II). Cancer Res. 1987; 47: 3000-3004.

6. Burger AM, Double JA, Newell DR. Inhibition of telomerase activity by cisplatin in human testicular cancer cells. Eur J Cancer. 1997; 33: 638-644.

7. Xu Q, Bauer R, Hendry BM, Fan TP, Zhao Z, Duez P, Simmonds MSJ, Witt CM, Lu A, Robinson N, Guo D, Hylands PJ. The quest for modernization of traditional Chinese medicine. BMC Complement Altern Med. 2013; 13 (1): 132.

8. Bodeker G, Kronenberg F. A public health agenda for traditional, complementary and alternative medicine. Am J Public Health. 2002; 92 (10): 1582-1591.

9. Craig WJ. Health-promoting properties of common herbs. Am J Clin Nutr. 1999; 70 (3): 491S-499S.

10. Sahoo N, Manchikanti P, Dey S. Herbal drugs: Standards and regulation. Fitoterapia. 2010; 81(6): 462-71.

11. Huang GC, Chien TY, Chen LG, Wang CC. Antitumor effects of zerumbone from Zingiber zerumbet in P-388D1 cells in vitro and in vivo. Planta Med. 2005; 71: 219-224.

12. Sung B, Jhurani S, Ahn KS, Matsuo Y, Yi T, et al. Zerumbone down-regulates chemokine receptor CXCR4 expression leading to inhibition of CXCL12-induced invasion of breast and pancreatic tumor cells. Cancer Res. 2008; 68: 8938-8944.

13. Abdul AB, Al-Zubairi AS, Devi ND, Wahab SI, Zain ZN, Ruslay S, Syam M M. Anticancer activity of natural compound (zerumbone) extracted from Zingiber zerumbet in human HeLa cervical cancer cells. Int J Pharmacol. 2008; 4: $160-168$.

14. Abdelwahab SI, Abdul AB, Alzubairi AS, Elhassan MM, Syam MM. In vitro ultra morphological assessment of apoptosis induced by zerumbone on human cervical cancer cells (HeLa). J Biomed Biotech, (2009), Article ID 769568, $10 \mathrm{pp}$.

15. Abdelwahab SI, Abdul AB, Devi D, Ehassan MM, Al-zubairi AS, Mohan S, Mariod AB. Regression of cervical intraepithelial neoplasia by zerumbone in female Balb/c mice prenatally exposed to diethylstilboestrol: Involvement of mitochondria-regulated apoptosis. Exp Toxicol Pharmacol. 2010; 62(5): 461-469.

16. Yodkeeree S, Sung B, Limtrakul P, Aggarwal BB. Zerumbone enhances TRAIL-induced apoptosis through the induction of death receptors in human colon cancer cells: evidence for an essential role of reactive oxygen species. Cancer Res. 2009; 69: 6581- 6589.

17. Kim M, Miyamoto S, Yasui Y, et al. Zerumbone a tropical ginger sesquiterpene, inhibits colon and lung carcinogenesis in mice. Int J Cancer, 2009; 124: 264-271.

18. Sung B, Murakami A, Oyajobi BO, Aggarwal BB. Zerumbone abolishes RANKL-induced NF- B activation, inhibits osteoclastogenesis, and suppresses human breast cancer-induced bone loss in athymic nude mice. Cancer Res. 2009; 69: 1477-1484.

19. Tsuboi K, Matsuo Y, Shamoto T, Shibata T, Koide S, et al. Zerumbone inhibits tumor angiogenesis via NF- $\mathrm{KB}$ in gastric cancer. Oncol Rep, 2014; 31: 57-64.

20. Bustamam A, Ibrahim S, Devi N, Hakim MN, Al-Zubairi AS, Syam MM. The establishment and use of an in vivo animal model for Cervical Intra-epithelial Neoplasia. Int J Cancer Res. 2008; 4 (3): 61-70.

21. Tanaka T, Shimizu M, Kohno H, Yoshitani S, Tsukio 
Y, Murakami A, Safitri R, Takahashi D, Yamamoto K, Koshimizu K, Ohigashi H, Mori H. Chemoprevention of azoxymethane-induced rat aberrant crypt foci by dietary ZER isolated from Zingiber zerumbet. Life Sci. 2001; 69: 1935-1945.

22. Tyagi AK, Singh RP, Agarwal C, Chan DCF, Agarwal R. Silibinin strongly synergizes human prostate carcinoma DU145 cells to Dox-induced growth inhibition, G2-M arrest, and apoptosis. Clin Cancer Res. 2002; 8: 3512-3519.

23. Kelloff GJ. Perspectives on cancer chemoprevention research and drug development. Adv Cancer Res 2000; 78: 199-334.

24. Sporn MB, Suh N. Chemoprevention of cancer. Carcinogenesis. 2000; 21: 525-530.

25. Swierenga SHH, Heddle JA, Sigal EA, Gilman JPW, Brillinge RL, Douglas GR, Nestmann ER. Recommended protocols based on a survey of current practices in genotoxicity-testing laboratories. IV. Chromosome aberration and sister-chromatid exchange in Chinese hamster ovary, V79 Chinese hamster lung, and human lymphocyte cultures. Mutat Res. 1991; 246: 301-322.

26. Al-Zubairi AS. Genotoxicity assessment of natural anticancer compound zerumbone in $\mathrm{CHO}$ cell lines. Int $\mathrm{J}$ Can Res. 2012; 8(4): 119-129.

27. Al-Zubairi AS, Abdul AB, Mohan SS. Evaluation of the genotoxicity of zerumbone in cultured human peripheral blood lymphocytes. Toxicol In Vitro. 2010; 24: 707-712.

28. Abdul AB, Wahab SI, Al-Zubairi AS, El-Hassan MM, Syam, $\mathrm{M}$ M. Anticancer and antimicrobial activities of zerumbone from the rhizomes of Zingiber zerumbet. Int. J. Pharmacol. 2008; 4(4): 301-304.

29. Azeddine E, Cunha M, Kirsch-Volders. Spindle poisons can induce polyploidy by mitotic slippage and micronucleated mononucleates in the cytokinesis-block assay. Mutagenesis. 1998; 13: 193-198.

30. Matsuoka A, Matsuura K, Sakamoto H, Hayashi M, Sofuni T. A proposal for a simple way to distinguish aneugens from clastogens in the in vitro micronucleus test. Mutagenesis. 1999; 14: 385-389.

31. Kirsch-Volders M, Sofuni T, Aardema M, Albertini S, D Eastmond et al. Report from the in vitro micronucleus assay working group. Mutat. Res./Genet. Toxicol Environ Mutagen. 2003; 540: 153-163.

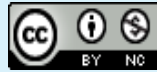

This work is licensed under a Creative Commons AttributionNon Commercial 4.0 International License. 